\title{
Assessment of Worst GEO Plasma Environmental Models for Spacecraft Surface Charging by SPIS
}

\author{
By Masao NaKamura, ${ }^{1)}$ Shinya NaKamura, ${ }^{1)}$ Ryota Kawachi, ${ }^{1)}$ and Kazuhiro Toyoda ${ }^{2)}$ \\ 1) Department of Aerospace Engineering, Osaka Prefecture University, Sakai, Japan \\ 2) Department of Electrical Engineering, Kyushu Institute of Technology, Kitakyushu, Japan
}

(Received June 30th, 2017)

\begin{abstract}
Assessment of the worst plasma environment for spacecraft surface charging in the geosynchronous Earth orbits (GEO) is important for spacecraft designs and operations, because it could cause spacecraft anomalies due to surface charging with resultant discharging arcs. The differential charging potential of spacecraft surfaces is considered to generate the harmful discharging arcs. There was no common standard of the worst GEO plasma environment for analysis of differential surface charging to prevent and mitigate the anomalies. Therefore in order to determine a new International Organization for Standardization (ISO) document for the purpose, a round-robin simulation was performed using the NASCAP-2k and MUSCAT. We perform surface charging simulations by Spacecraft Plasma Interaction Software (SPIS) as same as the round-robin simulation and evaluate the worst GEO plasma environmental models showing the detailed results. This study will contribute to a revision of the ISO document and also apply spacecraft charging risk estimations as space weather forecast.
\end{abstract}

Key Words: Spacecraft Charging, GEO Environment, Round-robin Simulation, SPIS

\section{Nomenclature}

\begin{tabular}{|c|c|}
\hline$E_{\max }$ & : maximum secondary electron yield energy \\
\hline $\mathrm{N}$ & $:$ number density $\left(\mathrm{m}^{-3}\right)$ \\
\hline $\mathrm{T}$ & $:$ temperature $(\mathrm{eV})$ \\
\hline$\delta$ max & : maximum secondary electron yield \\
\hline e & : electron \\
\hline i & : ion \\
\hline
\end{tabular}

\section{Introduction}

The worst plasma environment in the geostationary Earth orbit (GEO) frequently causes anomalies due to surface charging with resultant discharging arcs and occasionally damages space infrastructure systems for communication, broadcast, meteorological forecasting, navigation, etc. The discharging arcs occur because of the potential difference of the spacecraft surfaces. To prevent and mitigate these anomalies, charging assessments for the worst charging plasma environment by spacecraft charging analysis software are important for spacecraft designs and operations. The various worst GEO environmental models that measured in-situ by suitable instrumented spacecrafts are published. However, there was no international standard model for the worst surface charging assessment. To establish the proper realistic standard model, a round-robin simulation was performed using the major spacecraft charging analysis software, NASA/Air Force Spacecraft Charging Analyzer Program (NASCAP-2k) and Multi-Utility Spacecraft Charging Analysis Tool (MUSCAT). ${ }^{1)}$ In the round-robin simulation, surface potentials of a generic spacecraft model are calculated in both daylight and night-time (eclipse) charging under the several worst GEO plasma environmental models. As these efforts, the ISO 19923:2017 entitled "Space environment (natural and artificial) - Plasma environments for generation of worst case electrical potential differences for spacecraft"2) will be published. Following the round-robin simulation, results of the similar simulations using the other major spacecraft charging analysis software, Spacecraft Plasma Interaction Software (SPIS) and COULOMB-2, were published. ${ }^{3,4)}$ Since a simplified spacecraft model and a different charging scenario from the round-robin simulation are used in the SPIS simulation, ${ }^{3)}$ its results are not adequate for quantitative comparisons with the round-robin simulation results. Therefore, we performed the surface charging simulations by SPIS as same as the round-robin simulation and evaluate the worst GEO plasma environmental models showing the detailed results.

\section{Round-robin Simulation}

Figure 1 shows the generic GEO spacecraft model used to calculate the surface potential in the GEO charging environments. This model is originally constructed in a NASCAP-2k simulation, ${ }^{5)}$ and used in the round-robin simulation by NASCAP-2k and MUSCAT. ${ }^{1)}$ The body of the spacecraft is $1.86 \mathrm{~m}(\mathrm{X}) \times 1.55 \mathrm{~m}(\mathrm{Y}) \times 2.56 \mathrm{~m}(\mathrm{Z})$ covered with Optical Solar Reflector (OSR) on the two surfaces faced to the solar panels and black kapton on the other surfaces. The box on the top of the body is $0.62 \mathrm{~m} \times 0.516 \mathrm{~m} \times 0.62 \mathrm{~m}$ covered with NPaint (the other simulations after the NASCAP-2k simulation used kapton whose material properties are assumed to be the same as the NPaint). The 


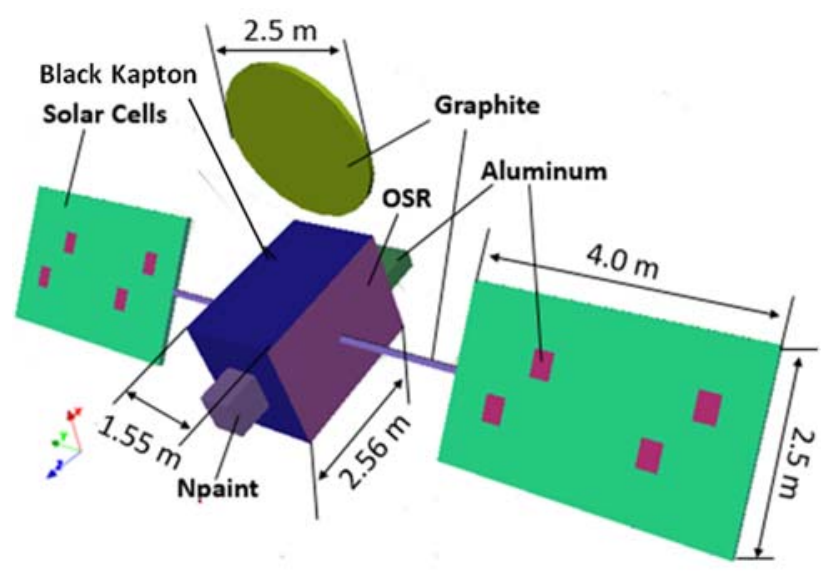

Fig. 1. The generic spacecraft model of the round-robin simulation constructed by SPIS.

aluminum box on the bottom of the body is $0.30 \mathrm{~m} \times 1.55 \mathrm{~m} \times$ $0.62 \mathrm{~m}$. The two solar panels with the aluminum patches between the solar cells on the front sides are $2.5 \mathrm{~m}$ (width) $\times$ $4.0 \mathrm{~m}$ (length) $\times 0.1 \mathrm{~m}$ (thickness) and twisted by 45 degrees from the X-Y plane. The back sides of the solar panels are covered with graphite. The graphite solar panel booms are 2.0 $\mathrm{m}$ long and $0.10 \mathrm{~m}$ squares in cross section. The graphite round antenna is $2.5 \mathrm{~m}$ in diameter and separates from the body by $0.3 \mathrm{~m}$. The angle of sunlight is perpendicular to the solar panel front surface in the daylight charging simulation. The material properties are listed in table 1. All conductive surfaces are electrically connected to the spacecraft chassis frame (spacecraft ground) and have a same absolute charging potential. This model is allowed to calculate surface charging for about 2000 seconds in both daylight and night-time for the worst GEO environmental models listed in table 2. The LANL-KIT, ATS-6, NASA Worst-Case models are single Maxwellian environmental models. The LANL-KIT model was only calculated by MUSCAT. Since the LANL-KIT model was picked up as a worst combination of the parameters used in the past study of the LANL geosynchronous satellite data ${ }^{6)}$ and not measured in-situ, there is doubtful whether it is a realistic model. The SCATHA-Mullen1, SCATHA-Mullen2, and ECSS-E-ST-10-04C (SCATHA 1979) models are double Maxwellian environmental models.

In the round-robin simulation, ${ }^{1)}$ they calculated the minimum potential (Min) and maximum potential (Max) of the spacecraft surfaces, and absolute (frame) potential (Frame) after charging for about 2000 seconds, and derived from these were, the largest differential potential (Max-Min), the inverted gradient maximum differential potential (Max-Frame), and the normal gradient maximum differential potential (Min-Frame). Although there was a divergence of charging calculations between NASCAP-2k and MUSCAT, the SCATHA-Mullen 1 model showed the largest maximum inverted gradient potential in both MUSCAT and NASCAP-2k simulations. Since the inverted gradient differential potential is practically critical for the discharges leading to the anomalies, they suggested that the SCATHA-Mullen 1 model can be reliably used as the worst GEO environmental model for the spacecraft surface charging assessments.

\section{GEO Spacecraft Charging Simulations by SPIS}

\subsection{SPIS}

We use the spacecraft charging analysis software of SPIS ${ }^{7,8)}$ which is based on the 3D Particle-In-Cell (PIC) method. The SPIS project aims at developing a software toolkit for spacecraft-plasma interactions modelling. The software is distributed as open source code on the SPIS home page. ${ }^{7)} \mathrm{We}$ use SPIS 5.1.8 on two Windows 7 64bit PCs, one of which has a Core i7 CPU and 16 GB RAM and the other of which has a Core i7 and 32 GB RAM.

\subsection{Simulation model}

We calculate the spacecraft surface potential by SPIS in the

Table 1. Material properties. ${ }^{1)}$

\begin{tabular}{|c|c|c|c|c|c|c|c|c|c|c|c|c|}
\hline $\begin{array}{l}\text { Surface } \\
\text { material }\end{array}$ & $\begin{array}{l}\text { Dielectric } \\
\text { Constant }\end{array}$ & $\begin{array}{l}\text { Thickness } \\
\text { (m) }\end{array}$ & $\begin{array}{l}\text { Bulk } \\
\text { Conductivity } \\
\left(\Omega^{-1} \mathrm{~m}^{-1}\right)\end{array}$ & $\begin{array}{l}\text { Atomic } \\
\text { Number }\end{array}$ & $\delta_{\text {max }}$ & $\begin{array}{l}E_{\max } \\
(\mathrm{keV})\end{array}$ & $\begin{array}{l}\text { Proton } \\
\text { Yield }\end{array}$ & $\begin{array}{l}\text { Proton } \\
\mathrm{Max} \\
\left(\mathrm{keV}^{* *}\right)\end{array}$ & $\begin{array}{l}\text { Photo- } \\
\text { emission } \\
\left(\mathrm{Am}^{-2}\right)\end{array}$ & $\begin{array}{l}\text { Surface } \\
\text { Resistivity } \\
(\Omega / \text { square })\end{array}$ & $\begin{array}{l}\text { Atomic } \\
\text { Weight } \\
(\mathrm{amu})\end{array}$ & $\begin{array}{l}\text { Density } \\
\left(\mathrm{kgm}^{-3}\right)\end{array}$ \\
\hline Graphite & $1 *$ & $1.00 \mathrm{E}-03$ & $-1^{*}$ & 4.5 & 0.93 & 0.28 & 0.455 & 80 & $7.20 \mathrm{E}-06$ & $-1 *$ & 12.01 & 2250 \\
\hline Aluminum & $1^{*}$ & $1.00 \mathrm{E}-03$ & $-1 *$ & 13 & 0.97 & 0.3 & 0.244 & 230 & $4.00 \mathrm{E}-05$ & $-1^{*}$ & 26.98 & 2699 \\
\hline Black & 3.5 & $2.50 \mathrm{E}-06$ & $-1 *$ & 5 & 5.2 & 0.90 & 0.455 & 140 & $5.00 \mathrm{E}-06$ & $-1^{*}$ & 12.01 & 1600 \\
\hline kapton & & & & & & & & & & & & \\
\hline $\begin{array}{l}\text { Solar cells } \\
(\mathrm{MgF} 2)\end{array}$ & 3.8 & $1.25 \mathrm{E}-04$ & $1.00 \mathrm{E}-13$ & 10 & 5.8 & 1 & 0.244 & 230 & $2.00 \mathrm{E}-05$ & $1.00 \mathrm{E}+19$ & 20 & 2660 \\
\hline OSR & 4.8 & $1.50 \mathrm{E}-04$ & $1.00 \mathrm{E}-16$ & 10 & 3.3 & 0.5 & 0.455 & 140 & $2.00 \mathrm{E}-05$ & $1.00 \mathrm{E}+19$ & 20 & 2660 \\
\hline NPaint & 3.5 & $1.27 \mathrm{E}-04$ & $1.00 \mathrm{E}-16$ & 5 & 2.1 & 0.15 & 0.455 & 140 & $2.00 \mathrm{E}-05$ & $1.00 \mathrm{E}+16$ & 12.01 & 1600 \\
\hline
\end{tabular}

*Dielectric Constant $=1$, Conductance $=-1$ and Surface Resistivity $=-1$ mean the material is considering as a conductor in simulation. **A typographical error in Ref. 1) is corrected.

Table 2. Worst-case GEO space environmental models. ${ }^{1)}$

\begin{tabular}{lrrrrrrrr}
\hline Environment Name & $\mathrm{Ne} 1\left(\mathrm{~m}^{-3}\right)$ & $\mathrm{Te} 1(\mathrm{eV})$ & $\mathrm{Ne} 2\left(\mathrm{~m}^{-3}\right)$ & $\mathrm{Te} 2(\mathrm{eV})$ & $\mathrm{Ni} 1\left(\mathrm{~m}^{-3}\right)$ & $\mathrm{Ti} 1(\mathrm{eV})$ & $\mathrm{Ni} 2\left(\mathrm{~m}^{-3}\right)$ & $\mathrm{Ti} 2(\mathrm{eV})$ \\
\hline LANL-KIT & $5 \mathrm{E}+06$ & 13500 & - & - & $2.5 \mathrm{E}+05$ & 5000 & - & - \\
ATS-6 & $1.20 \mathrm{E}+06$ & 16000 & - & - & $2.36 \mathrm{E}+05$ & 29500 & - & - \\
NASA Worst-Case & $1.12 \mathrm{E}+06$ & 12000 & - & - & $2.36 \mathrm{E}+05$ & 29500 & - & - \\
SCATHA-Mullen 1 & $2.00 \mathrm{E}+05$ & 400 & $2.30 \mathrm{E}+06$ & 24800 & $1.60 \mathrm{E}+05$ & 300 & $1.30 \mathrm{E}+06$ & 28200 \\
SCATHA-Mullen 2 & $9.00 \mathrm{E}+05$ & 600 & $1.60 \mathrm{E}+06$ & 25600 & $1.10 \mathrm{E}+05$ & 400 & $1.70 \mathrm{E}+06$ & 24700 \\
ECSS-E-ST-10-04C (SCATHA 1979) & $2.00 \mathrm{E}+05$ & 400 & $1.20 \mathrm{E}+06$ & 27500 & $6.00 \mathrm{E}+05$ & 200 & $1.30 \mathrm{E}+06$ & 28000 \\
\hline
\end{tabular}




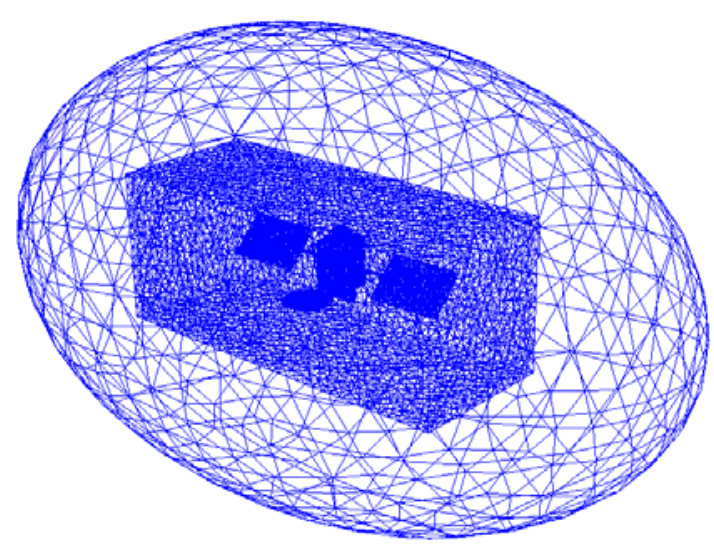

Fig. 2. Computational domain and mesh grids on the surfaces of the spacecraft model and two boundaries.

worst GEO charging plasma environmental models listed in table 2 as same as the round-robin simulation. The spacecraft model is constructed as shown in Fig. 1. Figure 2 shows the computational domain and mesh grids on the surfaces of the spacecraft model and two boundaries. The inner rectangular boundary is $8 \mathrm{~m}(\mathrm{X}) \times 20 \mathrm{~m}(\mathrm{Y}) \times 8 \mathrm{~m}(\mathrm{Z})$ with dense meshes and the outer spheroidal boundary is $40 \mathrm{~m}$ (long axis, $\mathrm{Y}) \times 24$ $\mathrm{m}$ (short axis, $\mathrm{X}$ and $\mathrm{Z}$ ) with sparse meshes. The capacitance of the spacecraft is set to $1 \mu \mathrm{F}$, which is higher than the typical value for GEO spacecraft but it allows to facilitate the simulation while keeping accurate final state and approximate transient phases. The simulation time step can be automatically adapted but we limit the maximum time step to $20 \mathrm{~s}$ in order to ensure a smooth potential evolution. The calculation times of the charging simulation vary depending on the environmental models. Using the optimized spacecraft model, it is taken about 1 3 hours for the night-time charging simulation and about 2 10 hours for the daylight charging simulation.

\subsection{Simulation results and discussions}

Figure 3 shows the spacecraft surface potential of the
SCATHA-Mullen 1 model after night-time charging for 2012 s. The maximum potential is obtained at a mesh of the solar cell surfaces far from the spacecraft body. The minimum potential is obtained at a mesh of the NPaint surfaces on the top box.

Figure 4 shows the time histories of the frame and average potential of each material surface for the SCATHA-Mullen 1 model in night-time (upper panel) and daylight (lower panel). The effects of secondary electron emissions generate a potential bump around 250 seconds as seen in the night-time charging profiles but is not so clear in the daylight charging simulation since the photoelectron is a dominant emission component. The spacecraft potential has almost come to a charging equilibrium at 2000 seconds.

Figure 5 shows the time histories of the frame and average potential of each material surface for the NASA Worst-Case model in night-time (upper panel) and daylight (lower panel). The spacecraft potential has not come to a charging equilibrium until 2000 seconds.

Figure 6 shows the time histories of the frame potential for the all environmental models in night-time (upper panel) and daylight (lower panel). The all potential profiles except for the ATS-6 model have approached to the steady values at 2000 seconds.

Figure 7 shows the time histories of the inverted gradient maximum differential potential (Max-Frame) calculated from the frame and the maximum averaged potentials of the material surfaces for the all environmental models in night-time (upper panel) and daylight (lower panel). In night-time, the all potential profiles have approached to the steady values until 2000 seconds. In daylight, the potential profiles of the double Maxwellian environmental models have approached to the steady values until 2000 seconds but those of the single Maxwellian environmental models have not.

Tables 3 and 4 show the calculated potential values of the spacecraft surfaces and their worst rankings after charging for about 2000 seconds in night-time and daylight, respectively. The maximum potential is obtained at a mesh of the solar cell
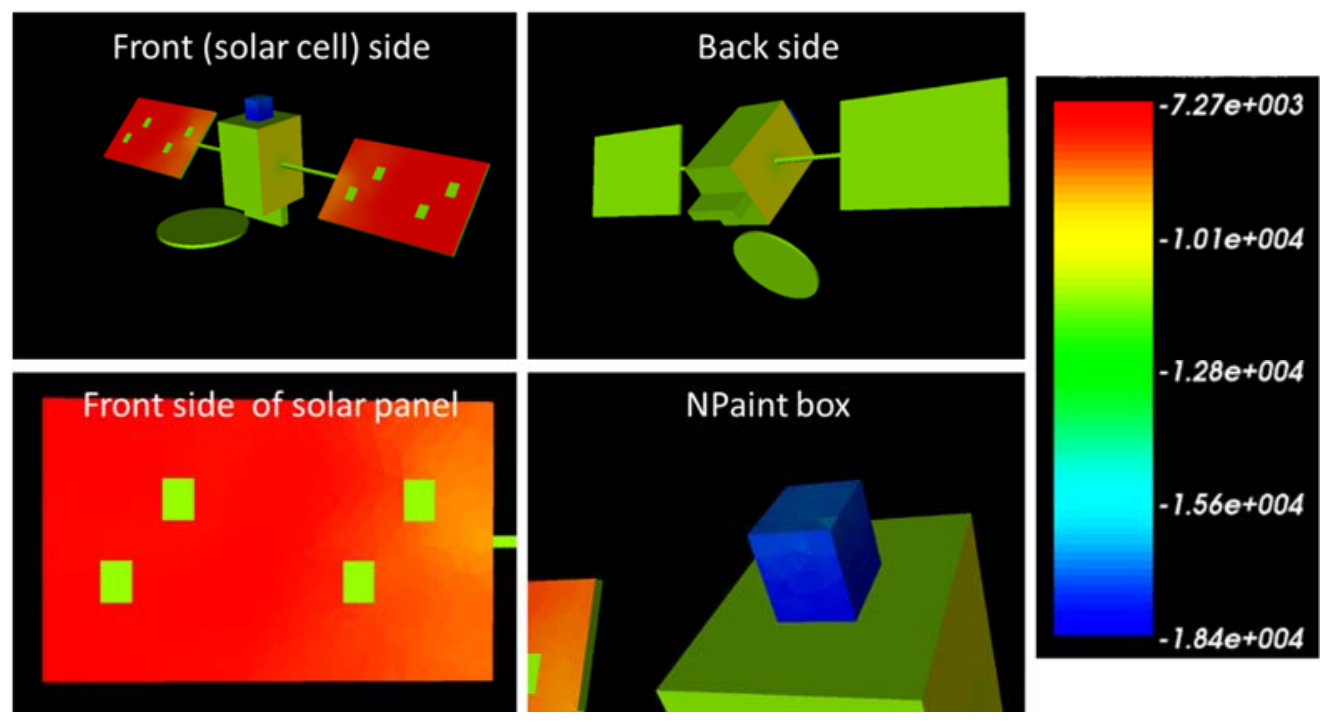

Fig. 3. The spacecraft surface potential of the SCATHA-Mullen 1 model after night-time charging for 2012 seconds. 
Trans. JSASS Aerospace Tech. Japan Vol. 16, No. 6 (2018)
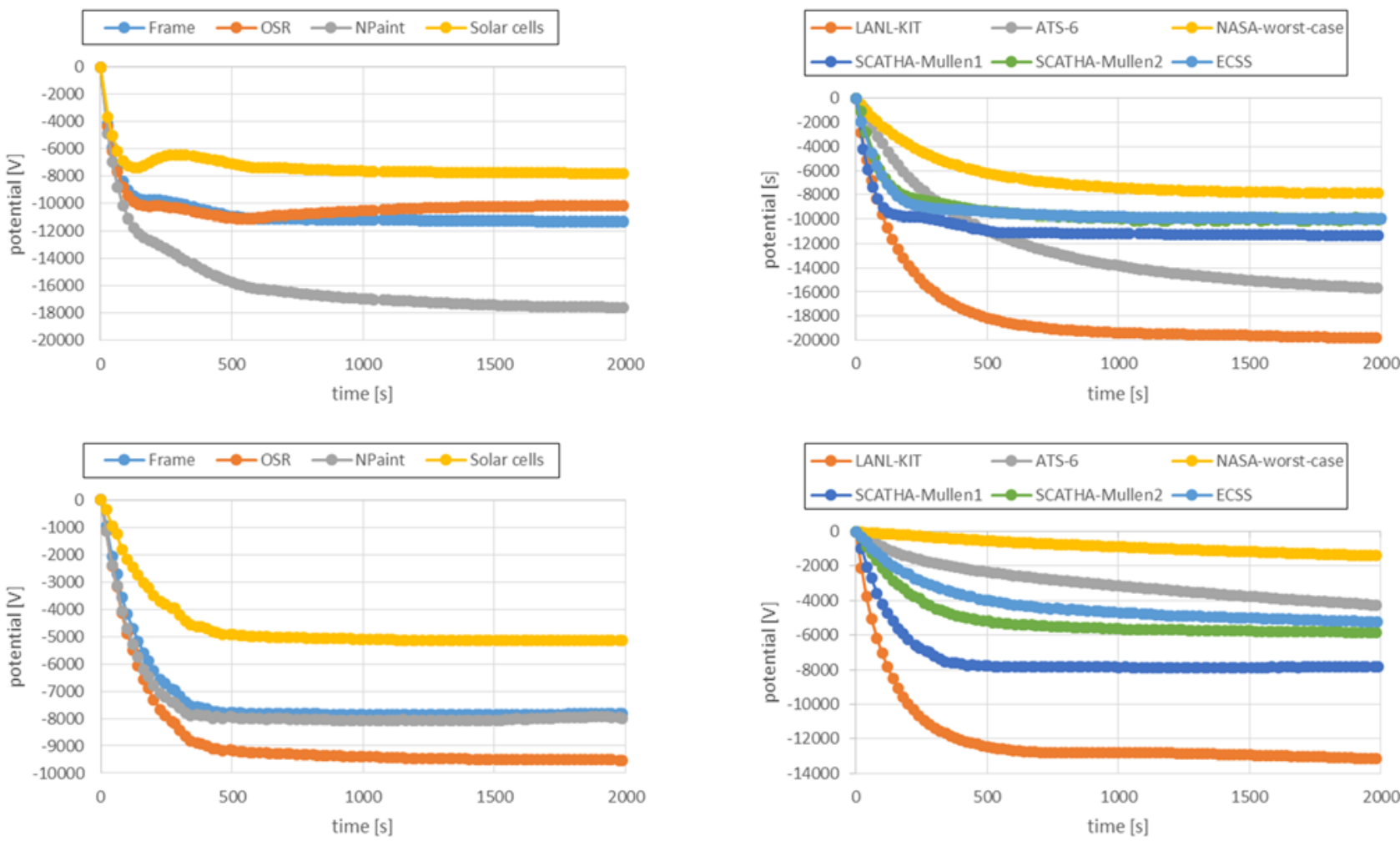

Fig. 4. Frame (ground) potential and average potential of each material surface for the SCATHA-Mullen 1 model in night-time (upper panel) and daylight (lower panel).
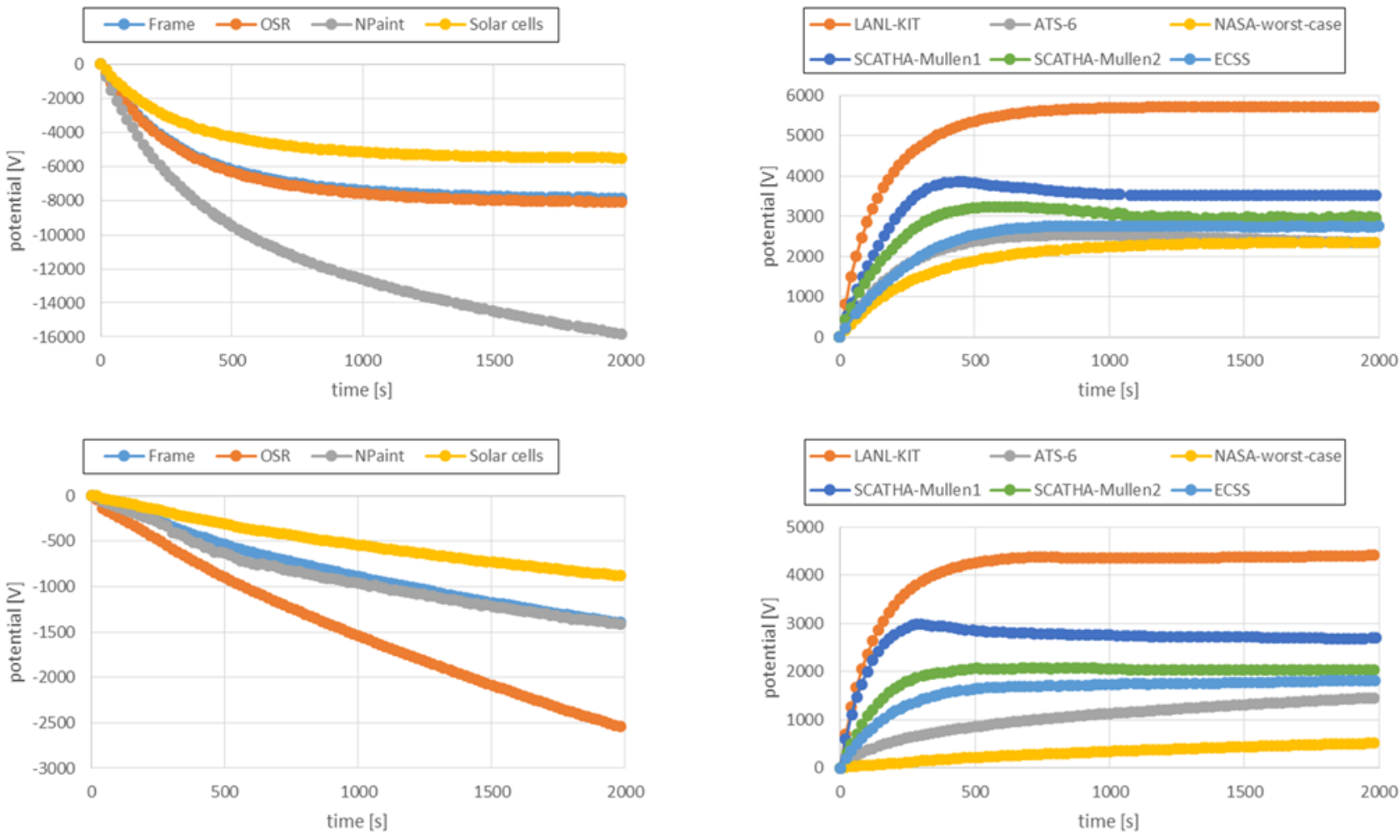

Fig. 5. Frame (ground) potential and average potential of each material surface for the NASA Worst-Case model in night-time (upper panel) and daylight (lower panel).

Fig. 6. Frame (ground) potential of the all worst GEO environmental models in night-time (upper panel) and daylight (lower panel).

Fig. 7. The inverted gradient maximum differential potential (Max-Frame) calculated from the frame and the maximum averaged potentials of the material surfaces in night-time (upper panel) and daylight (lower panel). 
Table 3. Night-time charging simulation results of SPIS. (Charging potential unit is V. Numbers in parentheses indicate worst rankings.)

\begin{tabular}{|c|c|c|c|c|c|c|c|}
\hline & Time (s) & Min & Max & Frame & Max-Min & Max-Frame & Min-Frame \\
\hline LANL-KIT & 2006 & -33979 & -13092 & $-19788(1)$ & 20887 & $6696(1)$ & -14191 \\
\hline ATS-6 & 2004 & -24307 & -13258 & $-15701(2)$ & 11049 & $2443(6)$ & -8606 \\
\hline NASA Worst-Case & 2002 & -15970 & -5152 & $-7874(6)$ & 10818 & $2722(5)$ & -8096 \\
\hline SCATHA-Mullen 1 & 2010 & -18289 & -7273 & $-11306(3)$ & 11016 & $4033(2)$ & -6983 \\
\hline SCATHA-Mullen 2 & 2009 & -17275 & -6652 & $-10092(4)$ & 10623 & $3440(3)$ & -7183 \\
\hline ECSS-E-ST-10-04C (SCATHA 1979) & 2019 & -17315 & -6786 & $-9935(5)$ & 10529 & $3149(4)$ & -7380 \\
\hline
\end{tabular}

Table 4. Daylight charging simulation results of SPIS. (Charging potential unit is V. Numbers in parentheses indicate worst rankings.)

\begin{tabular}{|c|c|c|c|c|c|c|c|}
\hline & Time (s) & Min & Max & Frame & Max-Min & Max-Frame & Min-Frame \\
\hline LANL-KIT & 2001 & -17598 & -8072 & $-13154(1)$ & 9526 & $5082(1)$ & -4444 \\
\hline ATS-6 & 2002 & -7875 & -2493 & $-4272(5)$ & 5382 & $1779(5)$ & -3603 \\
\hline NASA Worst-Case & 2001 & -2584 & -723 & $-1405(6)$ & 1861 & $682(6)$ & -1179 \\
\hline SCATHA-Mullen 1 & 2003 & -10195 & -4766 & $-7830(2)$ & 5429 & $3064(2)$ & -2365 \\
\hline SCATHA-Mullen 2 & 2003 & -8487 & -3518 & $-5846(3)$ & 4969 & $2328(3)$ & -2641 \\
\hline ECSS-E-ST-10-04C (SCATHA 1979) & 2005 & -8588 & -3061 & $-5231(4)$ & 5527 & $2170(4)$ & -3357 \\
\hline
\end{tabular}

surfaces far from the spacecraft body in both night-time and daylight. The minimum potential is obtained at a mesh of the NPaint surfaces on the top box in night-time but at a mesh of the OSR surfaces covered the spacecraft body in daylight. Although these potential values can change by a few percent due to the arbitrariness of the calculation domain and meshing and the randomness of particle generation and interaction in the PIC method, that may not change the worst rankings.

The results show that the LANL-KIT model is the worst environmental model for both the frame potential (Frame) and the largest inverted gradient potential (Max-Frame). These are different from the MUSCAT results in the round-robin simulation. However, as mentioned before, the LANL-KIT model is not a proper realistic model. Except for the LANL-KIT model, the SCATHA-Mullen 1 model is the worst environmental model for the largest inverted gradient differential potential (Max-Frame) in both night-time and daytime. These are consistent with the round-robin simulation results. For the frame potential, the SCATHA-Mullen 1 model is also worst in daylight but the ATS-6 model is worst in night-time. These are consistent with the NASCAP-2k results but not with the MUSCAT results in the round-robin simulation. We should investigate the reasons why these divergences of charging calculations are generated in future work.

\section{Conclusion}

We performed the spacecraft surface charging simulation by SPIS using the same spacecraft model and the same worst CEO environmental models as the round-robin simulation by NASCAP-2k and MUSCAT. The results show that the SCATHA-Mullen 1 model is the proper realistic worst model in both daylight and night-time charging according to the inverted gradient potential differences. This is consistent with the round-robin simulation results and the newly published ISO document. The results will contribute to a revision of the ISO document.

Since we can calculate the simulation model in the various GEO plasma environments and make comparisons with the other major spacecraft charging analysis software, we will also apply the simulation as the standard GEO spacecraft model for the Space Environment Customized Risk Estimation for Spacecraft (SECURES) of the space weather forecast Project for Solar-Terrestrial Environment Prediction (PSTEP).

\section{Acknowledgments}

The authors acknowledge Spacecraft Plasma Interaction System (SPIS) project. This work was supported by MEXT/JSPS KAKENHI Grant Number JP15H05813, Project for Solar-Terrestrial Environment Prediction (PSTEP) A01.

\section{References}

1) Toyoda, K. and Ferguson, D. C.: Round-Robin Simulation for GEO Worst-Case Environment for Spacecraft Charging, Proceeding of the 13th Spacecraft Charging Technology Conference, 171, 2014.

2) ISO 19923:2017, Space environment (natural and artificial) Plasma environments for generation of worst case electrical potential differences for spacecraft,

https://www.iso.org/obp/ui/\#iso:std:iso:19923:ed-1:v1:en (accessed August 1, 2017).

3) Liu, Y., Feng, W., Wang, S., Huang, J., Tang, X., and Wang, Z.: GEO Spacecraft potential estimation in worst-case environment by SPIS, Proceeding of the 14th Spacecraft Charging Technology Conference, 1140, 2016.

4) Novikov, L. S., Makletsov, A. A., and Sinolits, V. V.: Modeling of spacecraft charging dynamics using COULOMB-2 code, IEEE Trans. Plasma Sci., 45 (2017), pp. 1915-1918.

5) Ferguson, D. C., Hilmer, R. V. and Davis, V. A.: The Best GEO Daytime Spacecraft Charging Index, Journal of Spacecraft and Rockets, 52 (2015), pp. 526-543.

6) Hatta, S., Muranaka, T., Hosoda, S., Kim, J., Cho, M., Ueda, H., Koga, K., and Goka, T.: Multi-utility spacecraft charging analysis tool (MUSCAT): development overview, Proceeding of the 9th Spacecraft Charging Technology Conference, JAXA-SP-05-001E, 2005, pp. 492-498.

7) SPIS home page, http://dev.spis.org/projects/spine/home/spis, (accessed August 1, 2017).

8) Thiebault, B., Jeanty-Ruard, B., Souquet, P., Forest J., Matéo-Vélez, J.-C., Sarrailh, P., Rodgers, D., Hilgers, A., Cipriani, F., Payan, D., and Balcon, N.: SPIS 5.1: An Innovative Approach for Spacecraft Plasma Modeling, IEEE Trans. Plasma Sci., 43 (2015), pp. 2782-2788. 